\title{
Determinants of consanguinity and inbreeding coefficient in the multiethnic population of Mardan, Khyber Pakhtunkhwa, Pakistan
}

\author{
Muhammad Tufail', Atta Ur Rehman', Sajid Malik²,*
}

\begin{abstract}
Background: Despite the high sociocultural preferences in contracting marriages among close relatives in Pakistan, marked regional differences exist in the prevalence of consanguinity. There is great interest to elucidate the sociodemographic variables underlying the heterogeneity in consanguinity prevalence in the various populations. The present study was conducted in the Mardan district of Pakistan, the second largest multiethnic Pashtun metropolis.

Objective: To find determinants of consanguineous unions.

Methods: In a cross-sectional study design, a convenience sample of 1,202 ever-married men from 3 tehsils of Mardan district was recruited in an unselected manner and data regarding their marital union types and sociodemographic variables were obtained by a structured interview. Descriptive statistics and multivariable logistic regression analyses were used. Results: Consanguineous unions accounted for $44 \%$ of all marriages, and the inbreeding coefficient was calculated as 0.0258 . Regression analyses revealed that 6 variables were significant predictors of consanguinity, namely, tehsil, age, year of marriage, caste (zaat/biradari) system, area of house, and marriage arrangement of the respondent, while 6 other variables, namely, rural/urban origin, literacy, occupation, monthly income, household type, and number of family members, were not found to be significant. Regression analyses showed that there were different combinations of variables predictive of consanguinity among the various tehsils.

Conclusions: The prevalence of consanguinity in the Mardan district was found to be lower than that in many other districts of Pakistan. National regional differences exist in consanguinity, and the combination of predictive factors varies greatly.
\end{abstract}

Keywords: consanguinity, cousin unions, epidemiology, inbreeding coefficient, Khyber Pakhtunkhwa, Mardan, Pakistani, Pashtuns, public health

Consanguinity is common in many countries, particularly in developing nations and the Muslim world [1, 2]. In countries such as Iran, Turkey, Saudi Arabia, and Pakistan, consanguineous unions are favored both socially and culturally.
Consanguinity and inbreeding coefficient F (ICF) are of great interest because of their potential association with genetic anomalies and various health indicators. The prevalence of consanguinity has been shown to exhibit wide variation across

*Correspondence to: Sajid Malik, Human Genetics Program, Department of Animal Sciences, Faculty of Biological Sciences, Quaid-i-Azam University, Islamabad 45320, Pakistan, e-mail: malik@qau.edu.pk 'Department of Zoology, Hazara University, Mansehra 21300, Pakistan

${ }^{2}$ Department of Animal Sciences, Faculty of Biological Sciences, Quaid-i-Azam University, Islamabad 45320, Pakistan

O Open Access. $\odot 2017$ Muhammad Tufail et al., published by Sciendo. (c) BY-NC-ND This work is licensed under the Creative Commons Attribution NonCommercial-NoDerivatives 4.0 License. 
geography and cultures, and correspondingly, the determinants of consanguinity vary in different populations [3-5]. The most common sociodemographic factors associated with high consanguinity are rural origin, low literacy, poor socioeconomic status, extended household, and cultural norms [1, 6-8].

The underlying reasons for high consanguinity in Pakistan are sociocultural, including longstanding cultural norms of parents and family elders playing a key role in marriage decision-making, a sense of family obligation and reciprocity, pride in staying within the biradari or brotherhood system of clans that claim descent from a common ancestor, and strengthening the family relationship through marital bonds in the next generation. In addition, durability in marriage and keeping wealth within the family (in instances where families do possess wealth, be it land or other monetary assets) are some of the reasons of consanguinity [7]. Nonetheless, the prevalence of consanguinity varies greatly in different subpopulations because of differences in ethnicity and changes in social structure $[4,9]$.

In Pakistan, most studies of consanguinity have focused on various population subgroups in the Punjab province $[3,10,11]$, while there have been limited studies in other ethnic groups such as those in the Khyber Pakhtunkhwa (KPK) province (formerly known as North-West Frontier Province). Consanguinity has been reported from small and rather isolated populations of KPK, such as Swat [12], Sikhs in Peshawar [13], Malakand [14], Bajaur [4], and Dir Lower [9]. However, data on multiethnic and cosmopolitan populations of KPK are scarce. To address this scarcity of data, we have conducted a detailed study to assess the prevalence and correlates of consanguinity in the Mardan metropolis of KPK.

\section{Methods}

\section{Study population}

The study was undertaken in Mardan, the second largest district in the KPK province, both geographically and in population size. The population comprised various tribes of Pashtuns. The district is divided into 3 tehsils or administrative units, Mardan, Katlang, and Takht Bhai [15] (Figure 1). The district has a population of approximately 2 million, with an annual growth rate of $3 \%$ and average household size of 8.4 individuals [16]. Most of the population lives in rural areas [16, 17]. Overall, literacy in the district is $36 \%$ (53\% for men and $18 \%$ for women). Despite its increasing population, Mardan is socially conservative and the role of women is largely as homemakers and their sphere of influence is limited to within a narrow range of domestic responsibilities, with most of the financial decision-making controlled by men [18].

\section{Study design and sample collection}

This study was approved by ethical review committees of the Hazara University, Mansehra (F. No. 185/HU/Zool/2014/2305 and 2015/3145) and Quaid-i-Azam University, Islamabad. A population-based study was conducted in the Mardan district from September 2014 to March 2015. A convenience sample of ever-married men was recruited from 3 tehsils of Mardan. Each tehsil was divided into small geographic entities to cover all major towns and village clusters. There were 42 sampling

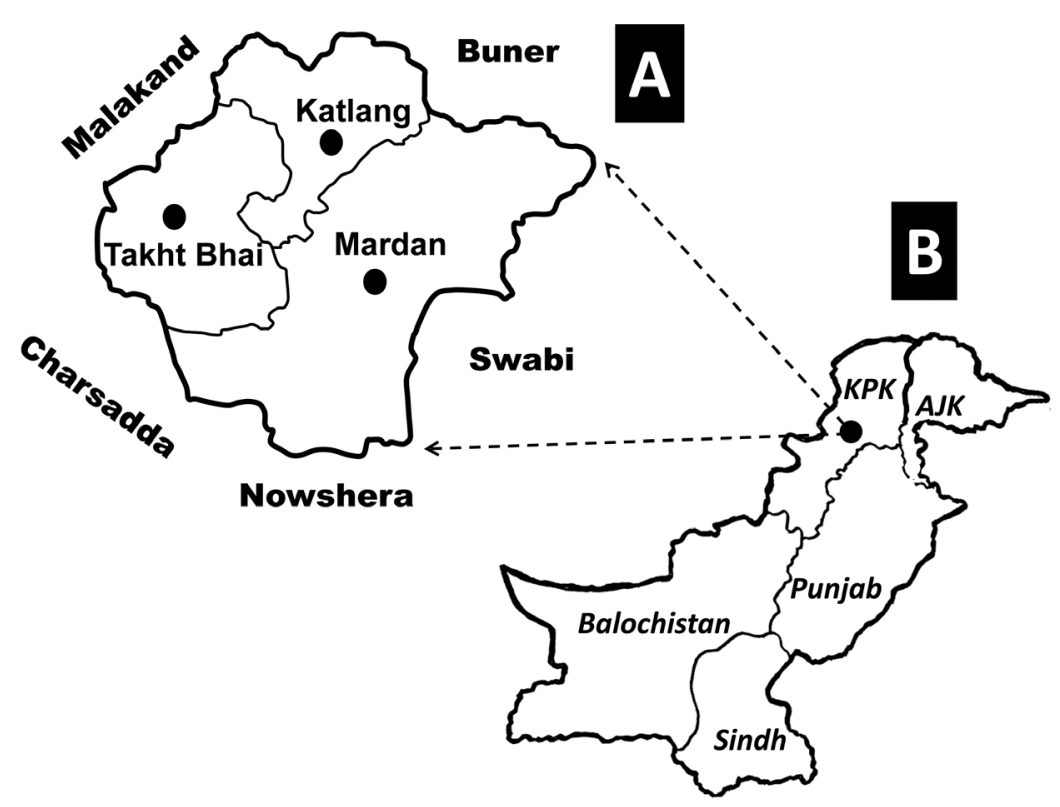

Figure 1. Map of the Mardan district (A) superimposed on a map of Pakistan (B). Three tehsils and the neighboring districts are shown in A 
sites: 13 from Mardan, 11 from Katlang, and 18 from Takht Bhai tehsils. Data on marital union types and sociodemographic and household variables were obtained through face-toface interviews using a structured pro forma. Because of the conservative sociocultural norms, recruitment of female respondents was not possible. The prospective respondents were approached in an unselected way in public places such as hospitals, markets, and community centers (hujra). Before embarking on this study, approval was taken from the administrative heads and local health authorities of the respective tehsils/ village clusters. In addition, verbal informed consent was witnessed and documented from each individual on the structured pro forma before data collection. Consent for approval and field work were convened by local resource people. All the respondents had permanent residence in the Mardan district, and only 1 individual was selected from a particular household. The total sample size was 1,202 men, aged 18-80 years (mean (SD) 39.25 years (10.03 years)). Data on individuals providing incomplete information were excluded from the analyses $(\mathrm{n}=83)$. For participants with more than one marriage, only the first marital union was considered in the analyses $(n=24)$.

\section{Definitions of sociodemographic variables}

Data were obtained on tehsil and rural or urban origin of the participants. Self-identified tribal affiliation was grouped into a primary Pashtun caste (zaat/biradari) such as Khattak, Yousafzai, and Mohmand. Information was gathered from the participants regarding their literacy and years of schooling. Literate participants were defined as those who had basic ability to read or write or were able to sign their name. We relied on self-identified occupations of participants, which were later recoded to the closest occupational categories established in the Pakistan Demographic and Health Survey [19]. The participants were asked their average monthly income (in Pakistani rupees), this was categorized into 5 income quintiles. As an indicator of socioeconomic status, various household variables, such as "area of house", "number of family members (household size)", and "family/household type", were also recorded. Information on the "size of house" was expressed in marla, which is a unit of occupied area ( 1 marla $=25.3 \mathrm{~m}^{2}$, exactly 1 square rod or 160 th of an acre in former British units). "Family/household types" were defined as either "nuclear" or "extended". 'Nuclear" families comprised a 1 couple household, and "extended" families comprised 3 or more overlapping generations dwelling as a unit. Information was also taken on "marriage arrangements", i.e., "traditionally arranged" and "arranged-love" marriages. Traditionally arranged marriages were those in which the parents or elders were involved in marriage decision; arranged-love marriages were those in which the individual was himself instrumental in the marriage decision and ceremony was subsequently contracted with the consent of both families.

There were 7 types of marital unions, which were classified into 2 broad categories, i.e., consanguineous unions and nonconsanguineous unions. Consanguineous unions comprised 4 types: marriages between double first cousins (DFCs), first cousins (FCs), first-cousin-once-removed (FCOR), and second cousins (SCs); while nonconsanguineous unions comprised 3 types: marriages between second-cousin-once-removed (SCOR), distantly related/biradari (DR), and non-related (NR) $[1,20]$. The FC unions were further classified into 4 subtypes: father's brother's daughter (FBD), father's sister's daughter (FSD), mother's brother's daughter (MBD), and mother's sister's daughter (MSD).

\section{Statistical analyses}

Data were analyzed using MS Excel and GraphPad Prism software (version 5). Standard summaries were generated; consanguineous unions and all marriages were cross-tabulated across the sociodemographic variables, and a chi-square contingency test was used to check the independence between the categorical variables [21]. ICF was estimated from the weighted proportion of individual consanguineous union types [1]. Bivariate logistic regression analyses were performed using STATA (version 11), and the results were expressed as unadjusted odd ratios (ORs). The dependent variable, i.e., consanguineous union, was taken as dichotomous, and the sociodemographic factors were coded as independent variables [22]. In each variable, the category with the lowest prevalence of consanguineous union was taken as the reference. For the multivariable regression analyses, a stepwise (likelihood ratio) logistic regression was performed. Only the significant variables were retained in the final model.

\section{Results}

\section{Sample characteristics}

A total of 1,202 unrelated men were enrolled. The sample size ranged from 314 individuals from Mardan tehsil to 571 from Takht Bhai tehsil (Table 1). In the overall sample, consanguineous unions accounted for $44.1 \%$ and ICF was 0.0258. Among the consanguineous unions, FC marriages were the most prevalent type (34.1\% of all marriages), followed by FCOR (4.8\%), SC (3.2\%), and DFC unions (2\%). In nonconsanguineous unions, marriages between unrelated individuals were most prevalent (43.3\%) (Table 1). 
Table 1. Distribution of major types of marital unions and ICF in 3 tehsils of the Mardan district

\begin{tabular}{|c|c|c|c|c|c|c|c|c|c|}
\hline \multirow{2}{*}{ Tehsil } & \multicolumn{4}{|c|}{ Consanguineous unions, $\mathrm{n}(\%)$} & \multicolumn{5}{|c|}{ Nonconsanguineous unions, $\mathrm{n}(\%)$} \\
\hline & DFC & FC & FCOR & SC & SCOR & DR & Unrelated & All marriages & ICF \\
\hline Mardan & $8(2.5)$ & $87(27.7)$ & $13(4.1)$ & $11(3.5)$ & $2(0.6)$ & $28(8.9)$ & $165(52.5)$ & $314(26.1)$ & 0.0223 \\
\hline Katlang & $6(1.9)$ & $100(31.5)$ & $16(5.0)$ & $12(3.8)$ & $4(1.3)$ & $45(14.2)$ & $134(42.3)$ & $317(26.4)$ & 0.0243 \\
\hline Takht Bhai & $10(1.8)$ & $223(39.1)$ & $29(5.1)$ & $15(2.6)$ & $4(0.7)$ & $69(12.1)$ & $221(38.7)$ & $571(47.5)$ & 0.0286 \\
\hline Total & $24(2.0)$ & $410(34.1)$ & $58(4.8)$ & $38(3.2)$ & $10(0.8)$ & $142(11.8)$ & $520(43.3)$ & $1,202(100)$ & 0.0258 \\
\hline
\end{tabular}

ICF, inbreeding coefficient F; DFC, double first cousin; FC, first cousin; FCOR, first-cousin-once-removed; SC, second cousin; SCOR, second-cousinonce-removed; DR, distantly related/biradari

The FC unions comprised $77.4 \%$ of the consanguineous marriages. Among these, FBD was the most prevalent type (35.4\%), followed by FSD (27.6\%), MBD (25\%), and MSD types (12\%) (Table 2). Hence, patrilineal unions outnumbered the matrilineal types $(62.9 \%$ vs $37.1 \%$, respectively; $P=0.0002)$. Moreover, cross-cousin unions were relatively higher in proportion than parallel-cousin unions $(52.7 \%$ vs $47.3 \% ; P=0.442$ ).

In the tehsil-wise samples, the highest consanguinity was observed in Takht Bhai (48.5\%), followed by Katlang (42.3\%) and Mardan (37.9\%) $(P=0.0073)$ (Tables 1 and 3). Detailed distribution of individual marriage types revealed that FC marriages had the highest representation in the Takht Bhai tehsil (39.1\% of all unions) and the lowest representation in the Mardan tehsil (27.7\%). Correspondingly, ICF was more pronounced in the Takht Bhai tehsil (0.0286), followed by Katlang (0.0243) and Mardan (0.0223) tehsils. Bivariate regression revealed a significantly high consanguinity in Takht Bhai $(P=0.007$; OR: $1.54 ; 95 \%$ CI: 1.166-2.045). Furthermore, consanguinity tended to be higher in individuals from rural areas compared with individuals from urban areas, while the differences were statistically not significant $(P=0.397)$ (Table 3).

Consanguinity tends to be higher among literate individuals $(45.7 \%)$ than among those who were illiterate (39.4\%); however, the difference was not quite significant $(P=0.056)$. Among the literate individuals, consanguinity declined with increasing level of literacy (Table 3); however, the difference was not significant $(P=0.34)$.

Four 5-year intervals for the year of marriage were defined (Table 3). The prevalence of consanguinity has tended to decrease slightly over time. However, the prevalence of consanguinity increased for younger individuals, and this appeared as a significant factor in multivariable regression.

Among the 20 Pashtun subcastes represented by recruited participants, there were 11 major tribe systems. Marked heterogeneity in consanguinity was evident among the tribes. The highest prevalence of consanguinity was observed in Pela Khel (59.7\%; OR = 6.66; 95\% CI: 2.06-11.65), followed by Afghan
Table 2. Distribution of types of FC unions in tehsils and rural/urban samples

\begin{tabular}{|c|c|c|c|c|c|c|}
\hline \multirow{2}{*}{ Variable } & \multicolumn{3}{|c|}{ FC marriage type (n) } & \multirow[b]{2}{*}{ MSD } & \multirow{2}{*}{$\mathbf{n}$} & \\
\hline & FBD & FSD & MBD & & & \\
\hline \multicolumn{7}{|l|}{ Tehsil" } \\
\hline Mardan & 33 & 26 & 20 & 8 & 87 & 27.7 \\
\hline Katlang & 38 & 23 & 23 & 16 & 100 & 31.5 \\
\hline Takht Bhai & 74 & 64 & 60 & 25 & 223 & 39.1 \\
\hline \multicolumn{7}{|c|}{ Rural/urban origin ${ }^{\#}$} \\
\hline Rural & 119 & 89 & 88 & 42 & 338 & 35.1 \\
\hline Urban & 26 & 24 & 15 & 7 & 72 & 30.0 \\
\hline
\end{tabular}

Total (\%) $\quad 145(35.4) \quad 113(27.6) \quad 103(25.1) \quad 49(12.0) \quad 41034.1$

"Distributions were statistically not significant

FC, first cousin; FBD, father's brother's daughter; FSD, father's sister's daughter; MBD, mother's brother's daughter; MSD, mother's sister's daughter

(49.2\%; OR $=5.1 ; 95 \%$ CI: 2.66-16.69) and Khattak (46.5\%; $\mathrm{OR}=3.92 ; 95 \%$ CI: $1.74-10.88 ; P=0.001$ ) (Table 4). Pela Khel and Khattak caste systems had the highest representations in the Takht Bhai tehsil, while Yousafzai and Mohmand had the highest representation in the Mardan tehsil. A detailed distribution of caste systems into 7 marriage types found that a higher consanguinity was a result of the high prevalence of FC unions (data not shown). Furthermore, the differences in the distribution of consanguineous and nonconsanguineous unions were highly significant $(P<0.001)$ (Table 4).

The prevalence of consanguinity was found inversely related to the area of house or dwelling size. The highest prevalence of consanguinity was found for individuals living in a small dwelling (55.3\%), and the lowest prevalence of consanguinity was found for individuals living in larger dwellings $\geq 20$ marla $\left(506 \mathrm{~m}^{2} ; P<0.0001\right)$. The number of family members was classified into 3 categories, i.e., " $\leq 5$ ", " $6-9$ ", and " $\geq 10$ " members per household. However, there was no significant difference in the consanguineous unions with respect to number of family members $(P=0.937)$. 
Table 3. Distribution of consanguineous unions, all marriages, and ICF in demographic variables of Mardan population

\begin{tabular}{|c|c|c|c|c|c|c|}
\hline \multirow{2}{*}{ Variable } & \multicolumn{2}{|c|}{ Consanguineous unions } & \multicolumn{2}{|c|}{ All marriages } & \multirow{2}{*}{$\begin{array}{r}\text { Univariate logistic } \\
\text { regression OR }\end{array}$} & \multirow{2}{*}{$95 \% \mathrm{Cl}$} \\
\hline & $\mathbf{n}$ & $\%$ & $\mathbf{n}$ & $\%$ & & \\
\hline \multicolumn{7}{|l|}{ Tehsil" } \\
\hline Mardan & 119 & 37.9 & 314 & 26.1 & Ref. & - \\
\hline Katlang & 134 & 42.3 & 317 & 26.4 & 1.20 & $0.872-1.650$ \\
\hline Takht Bhai* & 277 & 48.5 & 571 & 47.5 & 1.54 & $1.166-2.045$ \\
\hline Total & 530 & 44.1 & 1,202 & 100 & & \\
\hline \multicolumn{7}{|c|}{ Rural/urban origin } \\
\hline Rural & 430 & 44.7 & 962 & 80.0 & 1.13 & $0.849-1.507$ \\
\hline Urban & 100 & 41.7 & 240 & 20.0 & Ref. & - \\
\hline \multicolumn{7}{|l|}{ Literacy } \\
\hline Illiterate & 121 & 39.4 & 307 & 25.5 & Ref. & - \\
\hline Literate & 409 & 45.7 & 895 & 74.5 & 1.29 & $0.993-1.684$ \\
\hline \multicolumn{7}{|c|}{ Literacy level (years of schooling) } \\
\hline Up to 8 & 40 & 50.6 & 79 & 6.57 & 1.36 & $0.836-2.216$ \\
\hline $9-12$ & 213 & 47.0 & 453 & 37.7 & 1.18 & $0.892-1.555$ \\
\hline 13 and higher & 156 & 43.0 & 363 & 30.2 & Ref. & - \\
\hline \multicolumn{7}{|l|}{ Marriage year } \\
\hline 1985 or earlier & 57 & 47.5 & 120 & 9.98 & Ref. & - \\
\hline $1986-1995^{*}$ & 116 & 40.0 & 290 & 24.1 & 0.74 & $0.480-1.131$ \\
\hline $1996-2005^{*}$ & 215 & 46.0 & 467 & 38.9 & 0.94 & $0.631-1.409$ \\
\hline $2006-2015^{*}$ & 142 & 43.7 & 325 & 27.0 & 0.86 & $0.563-1.305$ \\
\hline \multicolumn{7}{|c|}{ Age of subject (years) } \\
\hline Up to $30^{*}$ & 117 & 47.8 & 245 & 20.4 & 1.47 & $0.966-2.246$ \\
\hline $30.1-40^{*}$ & 223 & 45.1 & 494 & 41.1 & 1.33 & $0.904-1.944$ \\
\hline $40.1-50$ & 136 & 42.2 & 322 & 26.8 & 1.18 & $0.786-1.767$ \\
\hline${ }^{3} 50$ & 54 & 38.3 & 141 & 11.7 & Ref. & - \\
\hline
\end{tabular}

"Distribution of consanguineous unions was statistically significant in the chi-square test statistics *Significant in regression analyses

ICF, inbreeding coefficient F; OR, odd ratio; $95 \% \mathrm{Cl}$, 95\% confidence interval; Ref., reference

We further investigated whether area of house was associated with "number of persons" in the house. A Spearman correlation did not find any significant correlation between these 2 variables $(r=-0.209)$. Furthermore, no significant correlation was found between area of house and monthly income or between number of persons and monthly income.

With respect to marriage arrangement, consanguinity was observed to be significantly higher in individuals who had arranged-love marriages (59.5\%) compared with those $(38.7 \%)$ who had traditionally arranged marriages $(P<0.0001$; OR: 2.32 ; 95\% CI: 0.552-0.723).

\section{Multivariable regression analyses}

In multivariable logistic regression, stepwise likelihood ratios were estimated. For convenience, all the parameters were initially put into two models. In the first model, the tehsil, rural/urban origin, literacy, age, occupation, and monthly income of the participant were considered. Among these, only tehsil emerged as a significant predictor of consanguinity. In the second model, year of marriage, caste system, "household type" (i.e., nuclear vs extended), area of house, number of family members, and marriage arrangement were used. Here, caste system, area of house and marriage arrangement were significantly associated with consanguinity. In the final model, all the parameters were incorporated. In this case, tehsil, age, year of marriage, caste system, area of house, and marriage arrangement were significant, while rural/urban origin, literacy, occupation, monthly income, household type, and number of family members were not (Tables 5 and 6). Regression analyses were repeated for the individual tehsils and revealed various combinations of variables predicting consanguinity in each tehsil (Table 6). 
Table 4. Distribution of consanguineous unions, all marriages, and ICF in socioeconomic variables of Mardan population

\begin{tabular}{|c|c|c|c|c|c|c|}
\hline \multirow{2}{*}{ Variable } & \multicolumn{2}{|c|}{ Consanguineous unions } & \multicolumn{2}{|c|}{ All marriages } & \multirow{2}{*}{$\begin{array}{r}\text { Univariate logistic } \\
\text { regression OR }\end{array}$} & \multirow{2}{*}{$95 \% \mathrm{C}$} \\
\hline & $\mathbf{n}$ & $\%$ & $\mathbf{n}$ & $\%$ & & \\
\hline \multicolumn{7}{|l|}{ Occupation } \\
\hline Professionals & 200 & 46.2 & 433 & 36.0 & 1.25 & $0.939-1.654$ \\
\hline Agriculture/farming & 146 & 40.8 & 358 & 29.8 & Ref. & - \\
\hline Unskilled manual & 75 & 45.2 & 166 & 13.8 & 1.20 & $0.826-1.735$ \\
\hline Sales/business & 44 & 42.3 & 104 & 8.7 & 1.06 & $0.684-1.657$ \\
\hline Skilled manual & 19 & 42.2 & 45 & 3.7 & 1.06 & $0.566-1.988$ \\
\hline Services & 19 & 42.2 & 45 & 3.7 & 1.06 & $0.566-1.988$ \\
\hline Others $(n<27)$ & 27 & 52.9 & 51 & 4.2 & 1.63 & $0.907-2.944$ \\
\hline \multicolumn{7}{|c|}{ Monthly income (in rupees, $\times 1,000$ ) } \\
\hline Up to 5 & 121 & 42.2 & 287 & 23.9 & Ref. & - \\
\hline$>5-10$ & 82 & 45.6 & 180 & 15.0 & 1.15 & $0.789-1.671$ \\
\hline$>10-20$ & 155 & 44.7 & 347 & 28.9 & 1.11 & $0.808-1.518$ \\
\hline$>20-40$ & 142 & 47.8 & 297 & 24.7 & 1.26 & $0.907-1.742$ \\
\hline$>40$ & 30 & 33.0 & 91 & 7.57 & 0.67 & $0.411-1.108$ \\
\hline \multicolumn{7}{|c|}{ Caste system ${ }^{\#}$ (zaat/biradari) } \\
\hline Makori & 8 & 18.2 & 44 & 3.7 & Ref. & - \\
\hline Dalazak & 12 & 30.8 & 39 & 3.2 & 2.00 & $0.718-5.571$ \\
\hline Dewan Khel* & 16 & 34.8 & 46 & 3.8 & 2.40 & $0.903-6.377$ \\
\hline Mohmand* & 39 & 35.5 & 110 & 9.2 & 2.47 & $1.046-5.841$ \\
\hline Gujjar* & 31 & 40.3 & 77 & 6.4 & 3.03 & $1.244-7.394$ \\
\hline Swati* & 22 & 42.3 & 52 & 4.3 & 3.30 & $1.285-8.475$ \\
\hline Utman Khel* & 22 & 45.8 & 48 & 4.0 & 3.81 & $1.467-9.881$ \\
\hline Yousafzai* & 69 & 46.0 & 150 & 12.5 & 3.83 & $1.670-8.797$ \\
\hline Khattak* & 195 & 46.5 & 419 & 34.9 & 3.92 & $1.778-8.630$ \\
\hline Afghan* & 30 & 49.2 & 61 & 5.1 & 4.36 & $1.743-10.883$ \\
\hline Pela Khel* & 37 & 59.7 & 62 & 5.2 & 6.66 & $2.657-16.693$ \\
\hline Others $(\mathrm{n}<39)^{*}$ & 49 & 52.1 & 94 & 7.8 & 4.90 & $2.060-11.654$ \\
\hline \multicolumn{7}{|l|}{ Family/household type } \\
\hline Nuclear & 406 & 43.7 & 929 & 77.3 & Ref. & - \\
\hline Extended & 124 & 45.4 & 273 & 22.7 & 1.07 & $0.817-1.406$ \\
\hline \multicolumn{7}{|l|}{ Area of house (marla) ${ }^{\#}$} \\
\hline Up to $5^{*}$ & 52 & 55.3 & 94 & 7.8 & 2.99 & $1.600-5.594$ \\
\hline $6-10^{*}$ & 218 & 50.8 & 429 & 35.7 & 2.50 & $1.496-4.166$ \\
\hline $11-15$ & 130 & 39.4 & 330 & 27.5 & 1.57 & $0.929-2.654$ \\
\hline $16-20$ & 106 & 39.7 & 267 & 22.2 & 1.59 & $0.932-2.717$ \\
\hline $20+$ & 24 & 29.3 & 82 & 6.8 & Ref. & - \\
\hline \multicolumn{7}{|l|}{ No. of family members } \\
\hline Up to 5 & 166 & 43.5 & 382 & 31.8 & Ref. & - \\
\hline $6-9$ & 272 & 44.6 & 610 & 50.7 & 1.05 & $0.809-1.355$ \\
\hline 10 or more & 92 & 43.8 & 210 & 17.5 & 1.01 & $0.722-1.425$ \\
\hline \multicolumn{7}{|l|}{ Marriage arrangement $t^{\#}$} \\
\hline Traditionally arranged & 345 & 38.7 & 891 & 74.1 & Ref. & - \\
\hline Arranged-love* & 185 & 59.5 & 311 & 25.9 & 2.32 & $0.552-0.723$ \\
\hline
\end{tabular}

"Distribution of consanguineous unions was statistically significant in the chi-square test statistics

*Significant in regression analyses

ICF, inbreeding coefficient F; OR, odd ratio; $95 \% \mathrm{Cl}$, 95\% confidence interval; Ref., reference 
Table 5. Significant predictors of consanguinity in Mardan population observed through multivariate logistic regression

\begin{tabular}{|c|c|c|c|c|}
\hline Variable & OR & Std. Err. & $P$ & $95 \% \mathrm{Cl}$ \\
\hline \multicolumn{5}{|l|}{ Tehsil } \\
\hline Mardan & Ref. & & & \\
\hline Katlang & 1.26 & 0.22 & 0.19 & $0.89-1.79$ \\
\hline Takht Bhai & 1.68 & 0.29 & 0.003 & $1.20-2.35$ \\
\hline \multicolumn{5}{|l|}{ Marriage year } \\
\hline$\leq 1985$ & Ref. & 0.16 & 0.048 & $0.33-0.99$ \\
\hline 1986-1995 & 0.57 & & & \\
\hline 1996-2005 & 0.53 & 0.17 & 0.048 & $0.28-0.99$ \\
\hline 2006-2015 & 0.34 & 0.12 & 0.003 & $0.17-0.69$ \\
\hline \multicolumn{5}{|l|}{ Age of subject (years) } \\
\hline Up to 30 & 2.52 & 0.92 & 0.011 & $1.23-5.14$ \\
\hline $30.1-40$ & 1.88 & 0.60 & 0.050 & $1.00-3.53$ \\
\hline $40.1-50$ & 1.45 & 0.41 & 0.18 & $0.84-2.52$ \\
\hline$\geq 50$ & Ref. & & & \\
\hline \multicolumn{5}{|l|}{ Caste system } \\
\hline Makori & Ref. & 2.42 & 0.004 & $1.60-12.88$ \\
\hline Dewan Khel & 4.54 & & & \\
\hline Mohmand & 2.81 & 1.29 & 0.024 & $1.14-6.92$ \\
\hline Gujjar & 3.20 & 1.52 & 0.015 & $1.26-8.14$ \\
\hline Swati & 4.49 & 2.26 & 0.003 & $1.67-12.06$ \\
\hline Utman Khel & 4.09 & 2.08 & 0.005 & $1.52-11.06$ \\
\hline Yousafzai & 4.05 & 1.79 & 0.002 & $1.70-9.61$ \\
\hline Khattak & 4.87 & 2.05 & 0.000 & $2.13-11.13$ \\
\hline Afghan & 4.56 & 2.23 & 0.002 & $1.75-11.89$ \\
\hline Pela Khel & 9.29 & 4.59 & 0.000 & $3.53-24.44$ \\
\hline Others & 4.93 & 2.26 & 0.001 & $2.01-12.12$ \\
\hline \multicolumn{5}{|l|}{ Area of house (marla) } \\
\hline $20+$ & Ref. & & & \\
\hline $16-20$ & 1.31 & 0.38 & 0.34 & $0.75-2.31$ \\
\hline $11-15$ & 1.28 & 0.36 & 0.38 & $0.74-2.24$ \\
\hline $6-10$ & 2.01 & 0.57 & 0.013 & $1.16-3.50$ \\
\hline Up to 5 & 2.61 & 0.90 & 0.005 & $1.34-5.12$ \\
\hline \multicolumn{5}{|l|}{ Marriage arrangement } \\
\hline Traditionally arranged & Ref. & & & \\
\hline Arranged-love & 2.58 & 0.37 & $<0.0001$ & $1.95-3.41$ \\
\hline
\end{tabular}

OR, odd ratio; Std. Err., standard error; $95 \% \mathrm{Cl}, 95 \%$ confidence interval; Ref., reference

\section{Discussion}

In Pakistan, about half of marriages are contracted between individuals who are SCs or closer $[4,11]$. In the population of Mardan, the prevalence of consanguinity was found to be lower than that reported for other populations of KPK and Punjab provinces. For instance, in districts of KPK,
Table 6. Significant predictors of consanguinity in individual tehsils as revealed by multivariate logistic regression

\begin{tabular}{|c|c|c|c|c|}
\hline Variable & OR & Std. Err. & $P$ & $95 \% \mathrm{Cl}$ \\
\hline \multicolumn{5}{|l|}{ Mardan tehsil $(\mathrm{n}=\mathbf{3 1 4})$} \\
\hline \multicolumn{5}{|l|}{ Rural/urban origin } \\
\hline Urban & Ref. & & & \\
\hline Rural & 1.82 & 0.47 & 0.019 & $1.10-3.01$ \\
\hline \multicolumn{5}{|l|}{ Marriage arrangement } \\
\hline Traditionally arranged & Ref. & & & \\
\hline Arranged-love & 4.10 & 1.10 & $<0.0001$ & $2.43-6.93$ \\
\hline \multicolumn{5}{|l|}{ Katlang tehsil $(\mathrm{n}=\mathbf{3 1 7})$} \\
\hline \multicolumn{5}{|l|}{ Area of house (marla) } \\
\hline Up to 5 & 5.63 & 3.61 & 0.007 & $1.60-19.80$ \\
\hline $6-10$ & 6.22 & 3.41 & 0.001 & $2.12-18.22$ \\
\hline $11-15$ & 2.20 & 1.21 & 0.15 & $0.75-6.44$ \\
\hline $16-20$ & 1.97 & 1.09 & 0.23 & $0.65-5.86$ \\
\hline $20+$ & Ref. & & & \\
\hline \multicolumn{5}{|l|}{ Marriage arrangement } \\
\hline Traditionally arranged & Ref. & & & \\
\hline Arranged-love & 3.68 & 1.09 & $<0.0001$ & $2.06-6.58$ \\
\hline \multicolumn{5}{|c|}{ Takht Bhai tehsil $(\mathrm{n}=\mathbf{5 7 1})$} \\
\hline \multicolumn{5}{|c|}{ Rural/urban origin } \\
\hline Urban & Ref. & & & \\
\hline Rural & 0.05 & 0.05 & 0.003 & $0.01-0.36$ \\
\hline \multicolumn{5}{|l|}{$\begin{array}{l}\text { Age of participant } \\
\text { (years) }\end{array}$} \\
\hline Up to 30 & 2.90 & 1.47 & 0.036 & $1.07-7.85$ \\
\hline $30.1-40$ & 2.11 & 0.96 & 0.10 & $0.87-5.14$ \\
\hline $40.1-50$ & 1.39 & 0.54 & 0.40 & $0.64-2.99$ \\
\hline $50+$ & Ref. & & & \\
\hline \multicolumn{5}{|l|}{ Marriage year } \\
\hline 1985 or earlier & Ref. & & & \\
\hline 1986-1995 & 0.91 & 0.37 & 0.81 & $0.41-2.01$ \\
\hline 1996-2005 & 0.73 & 0.33 & 0.49 & $0.29-1.79$ \\
\hline 2006-2015 & 0.48 & 0.24 & 0.15 & $0.18-1.30$ \\
\hline \multicolumn{5}{|l|}{ Caste system } \\
\hline Makori & Ref. & & & \\
\hline Dalazak & 1.58 & 0.96 & 0.45 & $0.48-5.17$ \\
\hline Dewan Khel & 1.00 & Empty & & \\
\hline Mohmand & 4.42 & 2.42 & 0.006 & $1.52-12.91$ \\
\hline Gujjar & 2.83 & 1.56 & 0.059 & $0.96-8.33$ \\
\hline Swati & 3.55 & 2.22 & 0.043 & $1.04-12.10$ \\
\hline Utman Khel & 6.95 & 4.17 & 0.001 & $2.15-22.51$ \\
\hline Yousafzai & 4.29 & 2.17 & 0.004 & $1.59-11.56$ \\
\hline Khattak & 7.44 & 3.54 & $<0.0001$ & $2.93-18.92$ \\
\hline Afghan & 3.23 & 1.82 & 0.038 & $1.07-9.74$ \\
\hline Pela Khel & 12.94 & 12.29 & 0.007 & $2.01-83.25$ \\
\hline Others $(\mathrm{n}<39)$ & 4.67 & 2.43 & 0.003 & $1.68-12.95$ \\
\hline
\end{tabular}

OR, odds ratio; Std. Err., standard error; $95 \% \mathrm{Cl}, 95 \%$ confidence interval; Ref., reference. 
consanguinity was reported to be $66 \%$ in Malakand in 2014 and 55\% in Peshawar in $2006[13,14]$. The prevalence of consanguinity in Mardan was also lower than the prevalence estimated for Bhimber in 2010 (62\%) [3], Sargodha in 2010-2011 (57\%) [11], and Gujranwala in 1985-1986 (59\%) [20]. The lowest prevalence of consanguinity ever reported in Pashtun populations was in Bajour (22.3\%) in 2012 [4] and Quetta $(31.6 \%)$ in 1994 [23].

By contrast with previous studies, in population in Mardan, we found no significant association between consanguinity and variables such as rural origin, literacy, occupation, income, family/household type, and number of family members $[6,7,11,20]$.

The prevalence of consanguinity was found to vary significantly across different tehsils and caste systems in the present population, which may show heterogeneity in consanguinity not only in different populations but also within the same population and different ethnicities within a region $[4,8]$. The high consanguinity in the Takht Bhai tehsil could be attributed to social and cultural obligations, in addition to the significant variables that emerged in multivariable regression analyses (Table 6). Most of the Pashtun populations including Khattak, Yousafzai, Utman Khel, Afghan, and Pela Khel are highly ethnocentric and only marry within their own caste system. In addition, a rate of low literacy compared to the provincial average might favor close marital unions because of unavailability of a suitable partner from outside their own family, although we did not determine the literacy of female marriage partners in the present study. Illiterate women are mostly restricted to household activities, have no access to the outside environment/external society, and rarely participate in the decision-making process regarding their marriage settlements $[4,18]$.

The lower prevalence of consanguinity in Mardan and Katlang tehsils could be the result of factors such as rapid urbanization, infrastructure development, and better transportation. Mardan is a tehsil capital, with a high rate of literacy (49\% in urban Mardan compared with 36\% in the overall district) [6]. Because of the availability of a better job market, people from adjoining districts are attracted toward urban Mardan to make their livelihoods. Therefore, Mardan has emerged as a metropolitan city where people of adjoining territories and ethnicities amalgamate. The lack of significant difference in the prevalence of consanguinity between rural and urban samples could be explained by the rapid urban population growth in Pakistan, whereby rapidly expanding cities engulf suburban rural communities such that the differences between rural and urban populations are mitigated [11].

When the year of marriage was examined, we found a slightly declining trend in the prevalence consanguineous unions over the past 20 years or so, but this was not significant. In the multivariable analyses, year of marriage was a significant variable in the overall sample as it was in the Takht Bhai tehsil, and a pronounced temporal decline in consanguinity was predicted (Tables $\mathbf{5}$ and 6). Hussain [7], based on evidence from national demographic surveys and other small-scale studies, remarked that there has been a slight decline in the preference for consanguineous marriages. By contrast, Ahmad et al. [9] found a sharp temporal rise in consanguinity in the Dir Lower district population of KPK. These authors argued that war and poor law and order resulted in the rise of consanguinity. Nonetheless, the stratification of consanguineous unions across age categories showed a rise in consanguinity with decreasing age. Younger age appeared to be a significant parameter in multivariable regression analyses in the overall data and in the Takht Bhai tehsil. Jabeen and Malik [20] found an increasing trend in consanguinity as the age of female respondents decreased. The authors attributed this trend to the deteriorating law and order situation at the line of control between Azad Jammu and Kashmir and Indian-occupied Kashmir, which caused separation of a large number of families and might have reduced the choice of partner. Year of marriage and age of respondent were significant predictors of consanguinity only in the Takht Bhai tehsil. The high consanguinity in younger individuals could also be the result of a decline in the mean age at marriage. Younger age at marriage is commonly seen in consanguineous unions [24].

Area of house was considered as an indicator of socioeconomic status. The current study showed that consanguinity was negatively associated with area of house, and a smallsized house was a significant predictor of consanguinity in the overall data and in the Katlang and Takht Bhai tehsils.

Here, we also analyzed marriage arrangement as a potential predictor of consanguinity. Marriage arrangement appeared to be a significant predictor in the overall data and in Mardan and Katlang tehsils. Because of the strict sociocultural stereotypes, "traditionally arranged" marriages were more prevalent in the current data. However, consanguinity was significantly higher in individuals who had arrangedlove marriages compared with individuals who had "traditionally arranged" marriages $(P<0.0001)$. This is consistent with the findings of Hina and Malik [11] and Jabeen and Malik [20]. The arranged-love marriages are convened by parents and are usually within close relatives. In these marriages, the bride or bridegroom, or both, influences the decision of parents, or engineers the situation almost entirely by themselves [25].

Among the 7 types of marital unions, FC and DR marriage types are helpful in getting an insight into the social structure of a population. FC unions indicate marriages among 
close blood relatives, while DR marriages may show the alliance with extended brotherhood or biradari or caste system. In traditional cultures, it is quite customary that the marriage decision is taken by the parents [7], particularly by the father [18]. One of the indicators of this matter is the pattern of alignment of cousins in FC unions. In the studied population, patrilineal unions had a higher occurrence than matrilineal unions $(P=0.0002)$. This is consistent with other studies conducted in Pakistan $[3,6,12]$. Patriarchal authority has the obligation of making the key decisions for the whole family. It is fundamentally the parents' responsibility to arrange marriages for their children, but older siblings may be actively involved if the parents die early or if they have been particularly successful in business or politics [26]. In the Pashtun tribal systems, an age-based hierarchy may exist [27]. By contrast, the biradari or group of male kin (the patrilineage) plays a significant role in social relations. Members of a biradari celebrate the major life events together. The biradari has traditionally served as a combined mutual aid society and welfare agency, arranging loans to members, assisting in finding employment, and contributing to the dowries of poorer families [26].

The caste/biradari system in the Muslim population is not comparable to the caste/social class system prevalent in Hindu or Indian culture [20]. In Pakistan, caste is a social rather than a religious institution, and more appropriate terms include clan, kin, and tribe (zaat/biradari) [28]. Castes are based on "lineage endogamy", with patrilineal cousin marriage forming the basis for the kin networks. A child inherits the caste of his or her father, so caste is fixed over generations [29]. We argue that urbanization and transition toward a cosmopolitan population may cause rise in nonconsanguineous unions but within the FC unions patrilineal unions would continue to dominate because of social and cultural norms.

The present study has several limitations. We could not acquire complete data regarding the parental marriage types of the respondents, and the marriage data of one generation have been used to calculate ICF. In populations where there is a long tradition of close unions, the calculation of ICF from one generation could be an underestimate. Data were not gathered from women because of social and cultural constraints. The convenience sampling of ever-married men may result in sampling error and may not truly represent the population. The income categories may not be truly representative of the economic status as respondents were generally reluctant to disclose their income. Similarly, occupation is a difficult thing to determine because of a wide range of occupational types and many competing scales. Furthermore, many individuals switch professions during different seasons of the year. Therefore, we relied on the self-reported occupation types.

\section{Conclusion}

Despite its limitations, the present study is to our knowledge, nevertheless, the first report on the prevalence of consanguinity and highlights important aspects of consanguineous unions in a multiethnic Pashtun metropolis. The present investigation found that consanguinity was not associated with sociodemographic variables such as rural/urban origin, literacy, occupation, monthly income, household type, and number of family members of male respondents; however, a different combination of variables appeared to be factors for consanguinity in the overall district of Mardan and among the individual tehsils. Regional differences exist in the prevalence of consanguinity, and the combination of factors for consanguinity varies greatly. A prospective study to determine various health indicators, such as fertility, child morbidity, and congenital abnormalities, in the population of Mardan appears warranted.

Author contributions. AUR and SM conceived and designed the study, MT and AUR acquired the data, and SM substantially analyzed and interpreted it. All authors drafted and critically revised the manuscript, approved the final version submitted for publication, and take responsibility for the statements made therein.

Acknowledgments. We highly appreciate the voluntary participation of respondents in this study. The helpful comments of Dr. Muhammad Zaman, Department of Sociology, and Dr. Mazhar Iqbal, Department of Economics, Quaid-i-Azam University (QAU), on the data are highly appreciated. This work was supported by the University Research Fund QAU. Research support was from the Higher Education Commission of Pakistan and Pakistan Science Foundation, Islamabad.

Conflict of interest statement. The authors have completed and submitted the ICMJE Uniform Disclosure Form for Potential Conflicts of Interest. None of the authors has any potential conflict of interest to disclose.

\section{References}

[1] Bittles AH. Consanguinity, genetic drift, and genetic diseases in populations with reduced numbers of founders. In: Speicher MR, Antonarakis SE, Motulsky AG, editors. Vogel and Motulsky's human genetics. Berlin, Heidelberg: Springer-Verlag; 2010. p. 507-728.

[2] Al-Gazali L, Hamamy H. Consanguinity and dysmorphology in Arabs. Hum Hered. 2014; 77:93-107.

[3] Bittles AH, Grant JC, Shami SA. An evaluation of consanguinity as a determinant of reproductive behaviour and mortality in Pakistan. Int J Epidemiol. 1993; 22:463-7. 
[4] Ahmad B, Rehman AU, Malik S. Consanguinity and inbreeding coefficient in tribal Pashtuns inhabiting the turbulent and war-affected territory of Bajaur Agency, North-West Pakistan. J Biosoc Sci. 2016; 48:113-28.

[5] Hussain R, Bittles AH. Assessment of association between consanguinity and fertility in Asian populations. J Health Popul Nutr. 2004 22:1-12.

[6] Hussain R, Bittles AH. The prevalence and demographic characteristics of consanguineous marriages in Pakistan. J Biosoc Sci. 1998; 30:261-75.

[7] Hussain R. Community perceptions of reasons for preference for consanguineous marriages in Pakistan. J Biosoc Sci. 1999; 31:449-61.

[8] Riaz HF, Mannan S, Malik S. Consanguinity and its socio-biological parameters in Rahim Yar Khan district, Southern Punjab, Pakistan. J Health Popul Nutr. 2016; 35:14. doi: 10.1186/s41043-016-0049-x

[9] Ahmad I, Rehman AU, Malik S. Determinants of consanguinity and inbreeding coefficient $f$ in Dir Lower district, north-west Pakistan: a multivariate approach. Iran J Public Health. 2016; 45:537-9.

[10] Shami SA, Siddiqui H. The effects of parental consanguinity in Rawalpindi city (Punjab), Pakistan. Biologia. 1984; 30:189-200.

[11] Hina S, Malik S. Pattern of consanguinity and inbreeding coefficient in Sargodha district, Punjab, Pakistan. J Biosoc Sci. 2015; 47:803-11.

[12] Wahab A, Ahmad M. Biosocial perspective of consanguineous marriages in rural and urban Swat, Pakistan. J Biosoc Sci. 1996; 28:305-13.

[13] Wahab A, Ahmad M, Shah SA. Migration as a determinant of marriage pattern: preliminary report on consanguinity among Afghans. J Biosoc Sci. 2006; 38:315-25.

[14] Sthanadar AA, Bittles AH, Zahid M. Increasing prevalence of consanguineous marriage confirmed in Khyber Pakhtunkhwa province, Pakistan. J Biosoc Sci. 2015; 48:418-20.

[15] Anonymous. [Internet]. 2015. [cited 2017 July 20]. Available from: http://kp.gov.pk

[16] Population Census Organization. Census Report of Mardan District [Internet]. Islamabad: Population Census Organization, Statistics Division, Government of Pakistan; 2017. [cited 2017 Jun 20]. Available from: $h t t p: / / w w w . p b s . g o v . p k / s i t e s / d e f a u l t /$ files//tables/District\%20at\%20a\%20glance\%20Mardan.pdf; http:// www.pbscensus.gov.pk/sites/default/files/bwpsr/kp/MARDAN_
BLOCKWISE.pdf; http://www.pbscensus.gov.pk/sites/default/files/ bwpsr/kp/MARDAN_SUMMARY.pdf

[17] Family Advancement for Life and Health (FALAH). Mardan: Baseline Household Survey [Internet]. Islamabad: Population Council; 2010 [cited 2017 June 20]. Available from: http://www.ndma.gov.pk/ Publications/Baseline\%20Household\%20Survey\%20Mardan.pdf

[18] Jalal-ud-Din M, Khan M. Socio-economic and cultural constraints of women in Pakistan with special reference to Mardan district, NWFP province. Sarhad J Agric. 2008; 24:485-93.

[19] NIPS. National Institute of Population Studies [Pakistan] and ICF International. Pakistan Demographic and Health Survey 2012-13 [Internet]. Calverton, MD, USA: National Institute of Population Studies and ICF International; 2013 [cited 2017 June 20]. Available from: http://www.nips.org.pk/abstract_files/PDHS\%20Final\%20 Report\%20as\%20of\%20Jan\%2022-2014.pdf

[20] Jabeen N, Malik S. Consanguinity and its sociodemographic differentials in Bhimber District, Azad Jammu and Kashmir, Pakistan. J Health Popul Nutr. 2014; 32:301-13.

[21] Garstman BB. Basic biostatistics. Sudbury, MA: Jones and Bartlett Publishers; 2006.

[22] Pagano M, Gauvreau K. Principles of biostatistics, 2nd ed. Pacific Grove, CA: Duxbury Press; 2000.

[23] Mian A, Mushtaq R. Consanguinity in population of Quetta (Pakistan): a preliminary study. J Hum Ecol. 1994; 5:49-53.

[24] Bittles A. The role and significance of consanguinity as a demographic variable. Popul Dev Rev. 1994; 20:561-84.

[25] Shaw A. Kinship, cultural preference and immigration: consanguineous marriage among British Pakistanis. J R Anthropol Inst. 2001; 7:315-34.

[26] Wiess AM. Traditional kinship patterns. In: Blood PR, editor. Pakistan: a country study. 6th ed. Washington: GPO for the Library of Congress; 1994, p. 100-3.

[27] Jacoby GH, Mansuri G. Watta satta: exchange marriage and women's welfare in rural Pakistan. The World Bank. 2008. p. 1-27.

[28] Bittles AH, Small NA. Consanguinity, genetics and definitions of kinship in the UK Pakistani population. J Biosoc Sci. 2016; 48:844-54

[29] Karachiwalla N. A teacher unlike me: social distance, learning, and intergenerational mobility in developing countries [Internet]. 2013 [cited 2017 July 20]. Available from: http://mpra.ub.uni-muenchen. de/64439/. 